Journal Plus Education, ISSN: 1842-077X, E-ISSN (online) 2068-1151 Vol XIX (2018), No. 1. pp. 313-320

\title{
ABILITIES AND SKILLS IN FIELDS OF SOCIAL WORK - CONCEPTS AND EMPIRICAL RESULTS
}

\author{
Matthias MOCH, Ph.D., \\ Faculty of Social Work - \\ Cooperative State University Baden-Württemberg - Stuttgart \\ moch@dhbw-stuttgart.de
}

\begin{abstract}
In the study programs of bachelor of social work there are different concepts to define abilities and skills as desirable outcomes of the successfully mastered curriculum. In Germany the curricula are based on a generalized "German Qualifications Framework of Social Work". Two studies are presented to find out, (1) how alumni evaluate the relevance of different aspects of competencies, (2) how these evaluations chances during the first two years after leaving university and (3) how the higher education in social work affects the ability of the alumni to evaluate critical situations in relation to appropriate skills.
\end{abstract}

Keywords: Social work; ability; competence; skill; study program; practicum; EQR;

\section{Introduction}

Higher education in social work has changed significantly in recent years. The graduated bachelor and master study programs are no more defined by study contents, but rather by basic vocational qualifications. Graduates of study should learn in a competency-oriented way. They have to prepare themselves for a process of lifelong learning. These changes go hand in hand with the hope that the transition from university to employment for graduates can be accomplished with less difficulty than before. Already the study should contain not only theory, but also pre-vocational parts and ideally combine theoretical teaching with professional practice. This is in contrast to the previous understanding of higher education, which focused primarily on the teaching of theories and expertise (Moch 2009; Treptow 2011).

One very basic concept for education and training was established as the European Qualification Framework (EQF). This concept divides the basic qualifications in general as: „knowledge“, „skills“ and ,responsibility an autonomy" (Europaen Commission 2018). These three areas of 
qualification are specified on eight levels beginng from elementary skills at school up to the doctorate level. Bachelor is situated at the level 6 . The keywords on this level are:

(1) "Advanced knowlege of a field of work or study, involving a critical understanding of theories and principles." (2) "Advanced skills, demonstrating mastery and innovation, required to solve complex and unpredictable problems in a specialized field of work or study." (3) "Manage complex technical or professional activities or projects, taking responsibility for decision-making in unpredictable work or study contexts; take responsibility for managing professional development of individuals and groups." (Europaen Commission 2018) (Highlighted by the author)

As a result of this discussion, also in the field of social work, was a reorientation of the study programs in the sense of concrete learning outcomes. The development of modular curricula has to be oriented to specific qualifications, which alumni should have achieved at the end of their study. As an attempt to refer to the principles of the German Qualifications Framework (DQR) on the professional field of social work, the German Board of the Faculties of Social Work (Fachbereichstag Soziale Arbeit) lined out a „Qualifications Framework Social Work (QR SArb)“ (Schäfer \& Bartosch 2016) as a framework for the Bachelor of Arts in Social Work. This framework includes seven headlines of basic qualifications on level 6 of the EQF:

- Knowlege and Understanding

- Description, Analysis and Valuation

- Planning and Conceptualisation

- Investigation and Reserach

- Organisation, Practice and Evaluation

- Professional Skills and Mindset

- Personality and Attitudes

All study programs of Social Work in Germany should define their learning outcomes in relation to these basic catalogue of abilities.

Studies and research questions

The categories of the German Framework define the abilities on an abstract level. Moreover there is no evidence about the specific relevance of each skill in the fields of professional social work. Our interest and research aim was to find out, whether the alumni as well as the professional social workers estimate these basic qualifications as relevant for their actual study and field practice.

During the last 15 years all in a whole we undertook three large projects on the theme of qualification and abilities of alumni of social work. 
(1) One did focus on the early professional biographies of alumni in Social Work (Moch 2013). (2) The second deals with the connection between personal competencies and institutional conditions (Moch 2018). (3) The third - just ongoing - study is about achieving qualifications in field-practice as part of the study program (Moch 2007, 2009; Moch \& Aparicio 2016).

In this article we report some results of the studies 1 and 2. In general we asked three questions: (1) Which abilities and skills do/should the alumni achieve by the bachelor study program of social work? (2) Does the study program qualify the alumni in relation to the challenges of the professional field practice? (3) How does the education of the alumni at the university influence the evaluation of critical situations? Our hypothesis was, that there would be a development through higher education at the university as well as through practice field experiences, which influence the valuation of necessary and adequate skills.

Methods

For study 1 we formed a questionnaire with specific items in relation to the seven qualification headlines of the German Qualification Framework of social work (as seen before). Then we started our assessment with 200 alumni, who had finished our study program and who were just employed in an institution of social work. We assessed our data in three consecutive points in time: Three month after leaving university, 15 month after leaving university and 27 month after leaving university.

For study 2 we worked out a questionnaire to evaluate how the social workers realize different aspects of critical situations, which should be managed in a proper way. Social workers with many years of experience in foster-care institutions were asked to evaluate each of 16 specific situations on 16 different ability-scales.

Results

First we look at the assessments of the relevance of abilities from the perspective of the alumni. Figure 1 shows the evaluations of the alumni and their changes over time on a scale from 1 (= high relevance) to 18 (low relevance). Most important for the alumni was the item ,personality“. This means aspects as: a stable, resilient and well-balanced personality with a pronounced sense for social tasks, independent in their definition of the limits and opportunities of their own actions. Second was the item: „Professional skills and mindset“. That means specific skills to work initiatively, to have responsibility / awareness of the risks of acting, willingness to continuously educate and update one's knowledge. At the lower end we find managing the organization and research. 
Figure 1: Alumni's evaluation of relevance of basic abilities Developments after leaving university $(\mathrm{N}=132 ; 98 ; 57)$

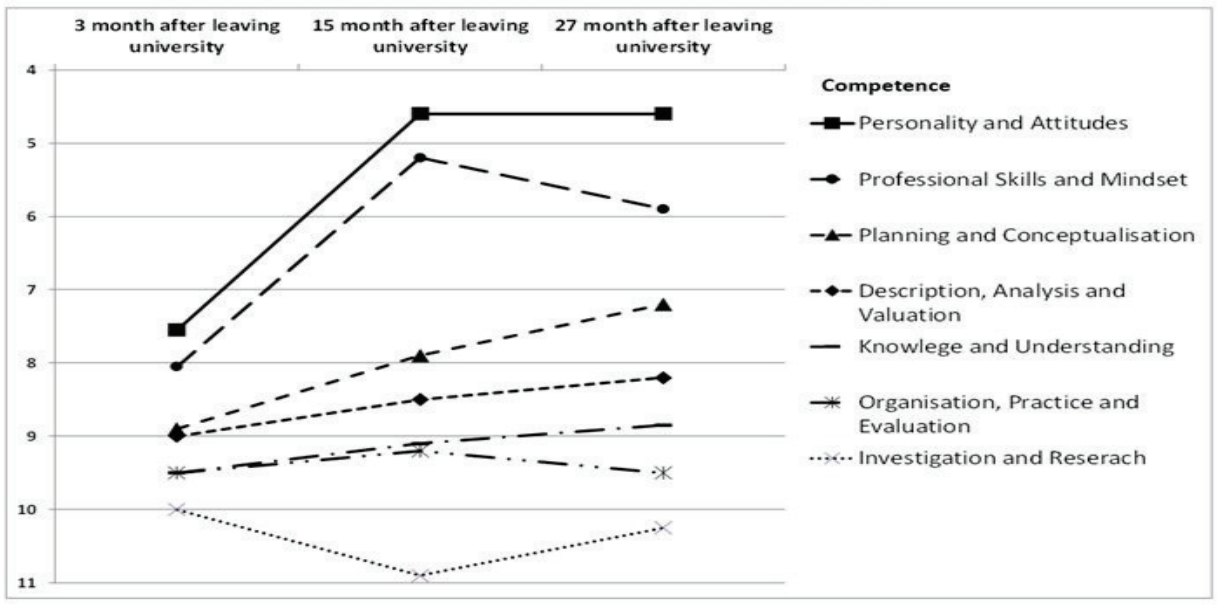

Fig.nr.1

The chart shows the development of the evaluations in the first 27 month of employment. It is to be noticed that the ranking of the seven dimensions has remained constant over the period of 2 years on the job. But: Over the first 27 months of work, the spectrum of these weightings has spread: some dimensions are increasingly important over time, others remain constant or even lose importance. As we can see, the relevance of „personality and attitudes“ increased clearly as the most important prerequisite for successful professional practice. Similarly, "professional skills and mindset" are seen as central competencies. In the middle range are skills related to planning / concept development, description, knowledge and organization. Research and research play a subordinate role.

Both dimensions of personality and professional attitudes, which are already important at the beginning, continue to gain high significance over the first 15 months of work. In the planning area, skills such as concept development, interdisciplinary work and concept implementation experience a continuous (and statistically meaningful) increase in significance over the period of study presented.

Other skills such as description, analysis, identification of tasks and method selection remain constant in their assessment, as well as the weight of theoretical and methodological knowledge, which is rated only two-and-aquarter years after starting work insignificantly higher than immediately after graduation. At the bottom of the spectrum are organizational skills such as developing new resources, methodologically supported investigation and research.

We did not only analyze the theory-related abilities, but also the skills, which are relevant in professional field practice (s. figure 2). Here we found, 
that abilities are emphasized, which also are highlighted in the European Qualifications framework! "Work in unpredictable circumstances and ability to respond to those in a properly way". (scale 1 (= high relevance) to 6 (low relevance).

Figure 1: Alumni's evaluation of relevance of basic abilities Developments after leaving university $(N=132 ; 98 ; 57)$

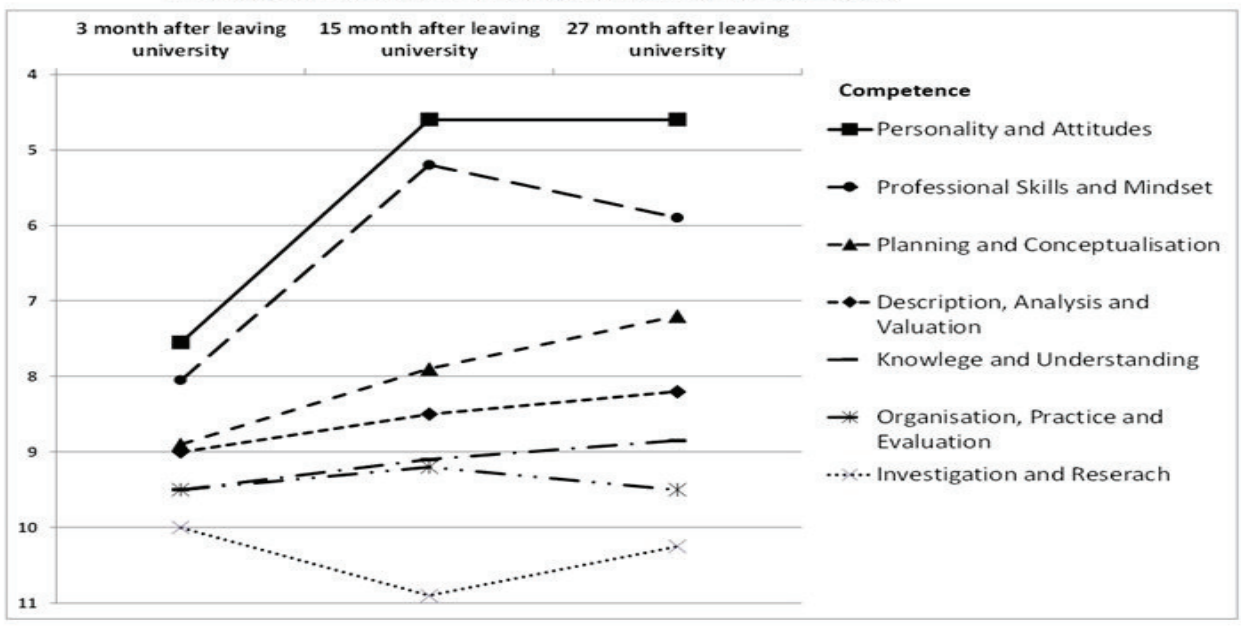

Fig.nr.2

Furthermore there were relevant topics: "Motivation others" and "working in teams"! These abilities were assessed as increasing very much in relevance during the first two years on the job. Once more the alumni underestimated the importance of scientific methods (see at the bottom). They also neglected intercultural aspects.

In a very new study we examined the professional strategies of social workers in every-day situations in institutions of child foster-care. We wanted to find out, how the social workers think about specific abilities, which they need to overcome critical situations. The participants of this study had to answer to 16 different vignettes of situations. The question was: „What do you think? Which abilities are necessary to manage this situation properly?" There were 16 ability-scales to be filled in for each situation.

To evaluate the data we used a form of ,correspondence analysis“, in which differences of estimations can be showed as distances in a twodimensional chart (Backhaus et al. 2011). The distance between two points can to be understood as how different the abilities were estimated referring to the situations in question. 
Figure 3: Correspondence analysis: Distribution of evaluation of different situations in relation to required abilities by level of education $(N=48)$
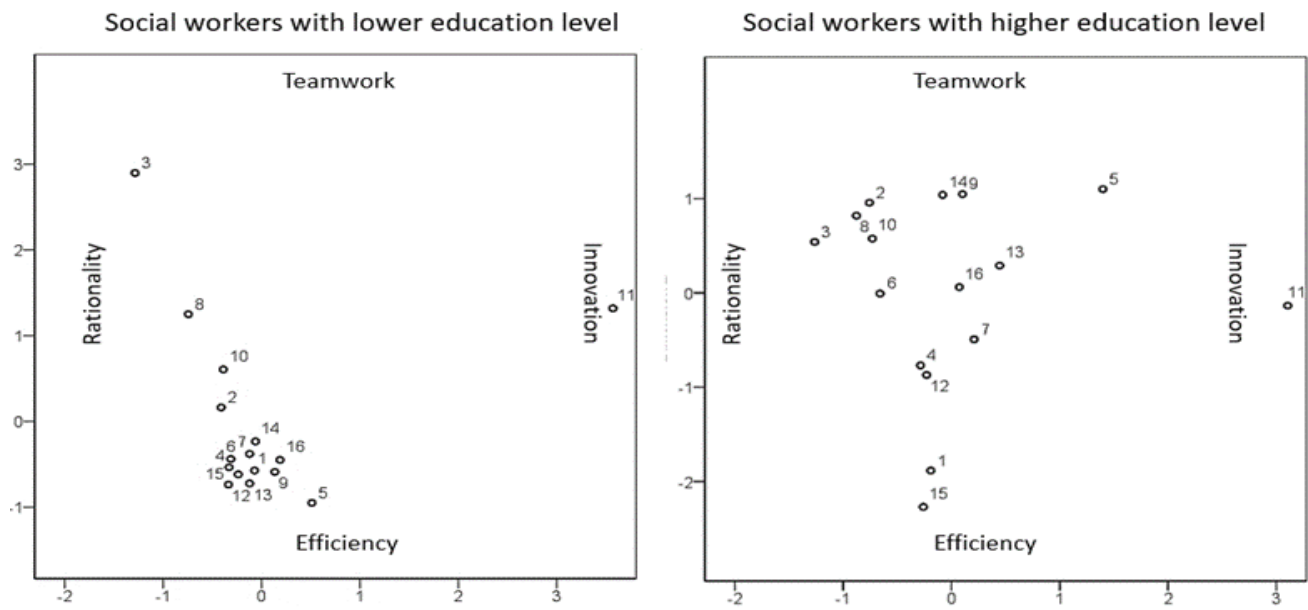

Fig.nr.3

Each point in figure 3 represents an evaluated situation (as mean of 24 individual estimations of the subsample). The distribution of the points shows the workface diversity of the estimated situations related to the appropriate abilities. The dimensions of the charts are labeled with terms, which correspond in a higher abstract way to the estimated competencies. For this presentation we reduced the complexity of the model to four dominant dimensions: „Rationality“; „Innovation“, Teamwork" and „Efficiency“.

We compared two groups of social workers: One group with lower qualifications (underneath university level) and the other group with higher qualification level (university level). As we can easily see, social workers with a lower qualification level estimated the 16 situation in a very narrow stretch near the dominant dimension of efficiency (coordinates $0 /-1$ ). Only some situations are estimated as related to teamwork and rationality.

In contrast to this result we can see the distribution of the estimations of social workers who are higher qualified: The situations were judged in much more differentiated way. Some are strong efficiency-orientated $(1 ; 15)$. Much more situations are estimated in relation to teamwork in combination with rationality and innovation. 
Journal Plus Education, ISSN: 1842-077X, E-ISSN (online) 2068-1151 Vol XIX (2018), No. 1. pp. 313-320

\section{Conclusions}

Within the German "Qualifications Framework of Social Work" the items ,personality“ and „professional skills" are outstanding in the assessments of abilities by young social workers after leaving university. The relevance of theses abilities increases in relation to the growing professional experience at the workplace. The challenges at the workplace affect obviously the estimation of the most important abilities which they had achieved at university. But the alumni underlined not only the importance of theoretical knowledge but also social and technical skills as flexibility, motivation of others, teamwork and efficacy which also increase clearly through practice experience. On the other hand the alumni underestimated the role of scientific skills as investigation and research. Within the everyday work these topics play obviously a marginal role. It seems that there is a clear gap between different sets of competencies, which are taught in university and which are assessed to be relevant in practical fields.

The bachelor program of social work should qualify the alumni not only in relation to very basic skills, but also train them to react appropriately to new and unexpected situations. As our results show higher education of social workers enable the alumni to differentiate between diverse necessities in relation to the specific situational context. Our conclusion is: Studying social work enables the alumni to widen their view in relation to different necessities. They can take in mind more aspects of competent managing different situations in different ways. So the alumni are better prepared by their skills for a very complex professional field. But the study at the university is not sufficient to overcome the challenges of practical problems. There is a clear evidence for the necessity to combine and coordinate the study curriculum with practical training in order to complete social workers professionalism.

\section{References}

Backhaus, K., Erichson, B., Plinke, W., \& Weiber, R. (2011): Multivatiate Analysemethoden. 13. Auflage. Heidelberg: Springer.

Europaen Commission (2018): Descriptors defining levels in the European Qualifications Framework (EQF) (https://ec.europa.eu/ploteus/en/content/descriptors-page, $30^{\text {th }}$ of may 2018) Moch, M. (2007). Praxis im dualen Studiengang Soziale Arbeit Erfahrungen Studierender unter der Lupe. Theorie und Praxis der Sozialen Arbeit, 58, p. 69-75.

Moch, M. (2009). Kompetenzerwerb im Praxisstudium Handlungskonstituierende Merkmale in „lehrreichen“ Situationen. Neue Praxis, 39, p. 620629. 
Moch, M. (2013). Early Professional Biographies - On the career entry and work experience of BA graduates in 'Social Work' In: International Conference on Technological Ecosystems for Enhancing Multiculturality (TEEM 2013) (URL: http://dl.acm.org/citation.cfm?id=2536620, 30 ${ }^{\text {th }}$ of may 2018)

Moch, M. (2016).

Moch, M. (2018). Kompetentes Handeln in stationären Erziehungshilfen. Wiesbaden: Springer.

Moch, M., \& Aparicio, P. (2016): Promoting student's competence through counseling by a practicum-tutor. In: Santos Rego, M.; Sotelino Sosada, L. \& Lorenzo Moledo, M. (Eds.) (2016): Aprendizaje-Servicio e innovacion en la universidad. Universidade Santiago de Compostela publications. p. $581-589$.

Schäfer, P., \& Bartosch, U. (2016). Qualifikationsrahmen Soziale Arbeit (QR SozArb). Fachbereichstag Soziale Arbeit. (http://www.fbts.de/fileadmin/fbts/QR_SozArb_Version_6.0.pdf ). $16^{\text {th }}$ of april 2018.

Treptow, R. (2011). Handlungskompetenz. In Otto, H.-U. \& Thiersch, H. (Hrsg.), Handbuch Soziale Arbeit, München: Reinhardt, p. 601-608. 